\title{
Towards a Typology of Urban Gamification
}

\author{
Mattia Thibault \\ Tampere University of \\ Technology \\ mattia.thibault@tut.fi
}

\begin{abstract}
This paper aims to propose a tentative typology of urban play in the wider frame of gamification. Based on the semiotic features of urban spaces and of human activities within them. The paper starts by outlining the existing perspectives on urban gamification and by describing the semiotic feature of urban spaces. Based on these, the author constructs a brief typology of urban gamification in regard of the kind of action undertaken and how it involves the city. Finally, a few examples are analyzed by the mean of this typology, underlining how playful activities of urban gamification can influence the citizens' perception and interpretation of the urban environment.
\end{abstract}

\section{Introduction}

Play has always had its place in the city. From simple games like "don't walk on the pavement lines" to AR location-based games such as Pokémon Go, many playful practices use the urban spaces as their playground. Today, however, city-play is acquiring a new dimension: it is seen, more and more, as an antidote to the anonymity of the urban environment [25]. The inhabitants of cities feel increasingly powerless and disconnected in face of the changes brought by globalization and by the ICT revolution [17]. This is even more critical to vulnerable populations in a moment where the right to the city of lower classes, minorities and immigrants is often questioned [25]. Urban play, on the other hand, reinforces the perception of "city ownership": it is an activity that requires immersion and lighthearted engagement and is able to build communities around a shared experience [25].

Play, then, seems to emerge as a powerful tool capable of promoting senses of ownership, community, and belonging which all may contribute to improving urban life and the well-being of citizens. In order to study and understand better these practices, this paper aims to construct a typology of urban gamification activities. As many the efficacy of many of these activities seems to lie on the way the change the citizens' perception of the urban space, this paper will engage in this topic with a meaning-centered approach based on urban semiotics.

\section{Perspectives}

There are several perspectives that can be very relevant to any approach to urban play. First of all, that linked to the concept of "pervasive play". This expression indicates a set of play activities that blend with ordinary life, escaping their traditionally perceived boundaries in regard of space, time and participants [23]. This may involve both analogue play - such as the Manhattan Megaputt, in which the whole island of Manhattan was transformed in a gigantic mini putt playground - and digital games, generally involving location-based services and/or augmented reality, such as Niantic games Ingress and Pokémon Go.

The category of "urban games" can also be rather relevant to my approach. It encompasses playful liveaction activities, possibly involving the use of ICT devices, designed to take place in the urban environment and to use its specificities as one of their defining characteristics [8].

Although unrelated to the former perspectives, critical design [10] - and especially its speculative forms - can be also a powerful tool to intervene in city spaces with the use of play, or ludiform activities. Critical design is based on the idea that design can be a privileged way to reflect upon society. It includes design practices aiming at creating objects or spaces that elicit critical thinking from their audience and it is based on the idea that design should challenge the status quo, instead of reinforcing it. Some of the work of research centers such as the Pervasive Media Studio in Bristol or the Waag in Amsterdam, to mention some notable cases dealing with city-planning, is ascribable to critical design. 


\section{Gamification \& the city}

All these perspectives can be somewhat reunited and enshrined within that of gamification. The latter indicates the attempt of using game design elements and inducing a playful behavior in order to boost user engagement and increase the efficacy of non-game activities, both digital and not. Gamification can be implemented in a vast range of activities, from promoting exercising (exergames) to conditioning driving behaviors (the Swedish Speed Camera Lottery). The concept (born in the digital media industry between 2008 and 2010) has been applied especially to education and learning [27], business [34] and health [22].

Analytic approaches and theoretical frameworks are quite recent in the field and are articulated around a perspective focusing mainly on defining "game elements" and their efficacy [9] or on redefining gamification on the basis of the participant responses [16]. This second approach seems to be most efficient: as a recent study [14] points out, gamification's positive effects are greatly dependent on the context and on the final users of the activity.

Gamification has to be understood within the frame of ludicisation [4] (sometimes "ludification") of culture. This term is used to indicate the renegotiation of the boundaries of play that is ongoing in a large part of the World. As games become the most important cultural industry on the planet, play is more and more perceived as a fundamental tool for describing and understanding reality [30].

Play is, of course, a rather difficult activity to describe and even to define, as it is recognized in several seminal works $[3,28]$. What is important, to us, it the fact that playfulness works as an "oasis" separated from the routine of everyday life [12] where the players can free themselves, in a certain measure, from their social roles (as theorized by Bakhtin in his essay on the carnivalesque [2]).

It is thanks to these characteristics of playfulness, then, that actions of gamification - within the fertile soil of a ludicized culture - can have a powerful impact on the way citizens inhabit, use and cross the urban spaces.

\section{Semiotics and city-texts}

In order to ground and situate the different perspectives and ways of including playfulness in the cityscape, I will engage urban areas with a meaning- centered approach. Semiotics deals with how we make sense of the world and therefore offers several conceptual and analytical tools for understanding how we "read" the cities and how we could "re-write" them or, at least, propose alternative "readings" of them. According to this perspective playfulness is a mean to propose new ways of interacting with(in) cities. Delineating the semiotic features of urban spaces, then, will give us the means for constructing a typology of urban gamification.

Already in 1980 Michel de Certeau in his L'invention du quotidien [6] proposed to consider the city as a textual form. This parallelism metaphorically already implicit in the expression "urban fabric" - leads de Certeau to consider the city as a real text, actualized (and transformed) by the practices of interaction and crossing of their inhabitants. The journey of the latter through the urban space, then, is nothing but an enunciation, by which the individuals take possession of the places and transforms them by introducing their own subjectivity. The city, then, is a text anything but fixed: it emerges as the result of practices of enunciation that, at the same time, actualize and deeply modify the urban spaces. In other words, according to the Certeau, moving through the city is like reading it out loud: it makes the text come to life but, at the same time, it modifies it, as it now includes the inflections as well as the choices of its citizens.

The metaphor of urban space as a text was later retrieved by semiotics as an important research direction. For semioticians [32] the city is not really a text, but rather acts as a text, and as a text it can be read, analyzed and understood [33] [21]. This can be rather useful for our purpose, as it will allow us to investigate the textual features of the city and, in particular, to outline those that can be of use in the creation of a typology of urban gamification.

\subsection{The semiotic features of the city}

A city is an organic whole - it can be understood and labeled as a unique thing - but at the same time it is characterized by an irreducible structural heterogeneity: a city encompasses countless texts of smaller scale (neighborhoods, streets, buildings, signs, street furniture, graffiti...). These smaller texts are a web of meaningful elements connected to each other [32]. It is an unstable and uncertain mingling, whose metamorphoses follow different times and rhythms, from the slow construction of new neighborhoods to the quick work of street-writers and the ephemeral presence of advertising posters. To this, we must add 
all the objects moving thought the city: goods, trucks, cars and the inhabitants of the city themselves, which cross its spaces and are distributed in different parts of the city giving meaning to the metropolitan landscapes.

This dual nature, of homogeneous text and of container of textualities of a smaller scale leads to a fundamental disappearance of a clear distinction between text and context [19]. If, on the one hand, the elements of larger size can become the context for those, incorporated, of smaller size (a neighborhood becomes the context of a building, a square that of a monument), the relationship between text and context is not limited to a simple relationship of incorporation. Therefore, it is possible that the objects of a smaller size, but with a greater symbolic efficacy, can become the context for larger-scale objects: "iconic" buildings and monuments are able to lessen the meaning of all that it is around them, creating a semiotic void that allows them to "shine".

This ability of smaller objects to recontextualize large environments around them is rather useful for several kinds of gamified activities that take place in the city. A single object, for example, can change the context of an entire square or neighborhood. The miniputt club and balls of Manhattan Mega-Putt, for example, are able to change (at least partially) the meaning of the whole surrounding city, which is recontextualized accordingly.

\subsection{Urban semiotic dynamics}

The kaleidoscopic mix of different elements that is the city features its own hierarchy. Its elements are organized according to an ideological stratification that tend to give greater emphasis and meaning to the buildings of the political and religious power, to monuments and "landmarks". Different kinds of power are often leaving deep marks in the cityscape, competing for the ownership of the highest building, placing their symbols in the most central squares, giving names to streets and buildings and neighborhoods.

Cities are the product of countless authors, eras and conceptions of urban spaces, to which correspond different strategies which meet, collide, mingle and overwrite each other in the city. The urban areas, then, become places whose elements are pervaded by an antagonistic tension: competing to obtain dominant positions (centrality, verticality, passages), attention (traffic) and prestige. This tension, however, is petrified in the buildings and streets of the city, which freeze them in a spatial arrangement.
While different powers compete for the right to shape the urban spaces, the communicative traces of most of the inhabitants of the city are relegated to a marginal role, limited to their ephemeral presence, or recur to billboards, signs, graffiti. The tension between citizens and power around the possibility to shape the city, however, is always present, and it can take form of open conflict (let's think of Gezi Park, in Istanbul [26]), that of activism, but also that of playful/gamified activities.

\section{Reading and writing the city}

To live and move through the city means, first of all, to be able to read and to interpret it. The experiential aspect of the city becomes even more important if, as in our case, we want to focus on the relationship between playfulness and urban spaces: gamifying city spaces is, first, an operation of interpretation and reinterpretation.

If we take in consideration the movement through the city, its complexity can be reduced to a basic opposition between "continuation" and "interruption". From this opposition we can outline two classes of urban objects: the passage (the road, the entrance, the side-walk, the pedestrian crossing, the square, the subway) and the obstacle (the wall, enclosure, barrier, the closed gate, but also the policeman directing traffic and the traffic lights) [29]. These two classes of objects regulate the actions of whoever moves into the urban space through a series of possibilities and prohibitions. On the one hand, passages and obstacles are, above all, signs of their possible uses - they convey the possibility or impossibility to cross them - while, on the other hand, they are also significant surfaces. The buildings of the city, for example, simultaneously block the view and become a surface on which to engrave messages, whether architectural (decorations), symbolic (flags, logos), commercial (advertising), social (mortuaries), identitarian (commemorative plaques) or ideological (political posters, graffiti) [21]. The passages, on the other hand, direct, regulate and guide the movement of the citizens and, therefore, they become the place where citizens enunciate the city by choosing a path or a behavior.

\subsection{Urban semiotic competence}

To read a rich text such as a city, it is necessary to choose some saliences - which items are significant, and which are trivial - and then to draw isotopies between them, in order to give a unique and organic meaning to the heterogeneous whole in which these 
diverse elements are immersed. Selecting the saliences, however, is not enough to be able to move consciously within the city. If it is true that in a social environment everything becomes a sign of its possible use, on the other hand, many objects are used differently by different individuals or at different times. Some objects may even be "reinvented" through practices contradictory of their original purpose. We should talk, then, of possible uses, in the plural form, thus implying the need for a second operation of selection and interpretation. The selection of a specific use between many possibilities is guided by an "urban semiotic competence" [32]: the ability to correctly interpret what the city tells us. This competence will guide the inhabitants in their tasks through the city. The city itself can hinder or facilitate the use of this competence in virtue of its legibility - the urban characteristic of assisting people in creating their mental maps and fostering wayfinding [20].

The urban semiotic competence is mainly made by expectations based on previous experiences. As cities are rarely hosting playful interactions, citizens are often surprised by the sudden presence of playfulness in places normally devoted to everyday-life activities. When Pokémon Go was launched, for example, there were several startled reactions by non-players sometimes even a hint of moral panic. The urban semiotic competence, however, is also something we can play with. Activities such as flash mobs (see 8.1) exploit it in order to create a sense of amazement at the sudden encounter with play in order to create engagement.

\subsection{Enunciating and writing the city}

The two classes of urban object that we discussed above, obstacles and passages, are products and objects both of writing practices and of enunciations.

Enunciation deals with tracing paths and moving thought the city. It includes strategic choices in wayfinding but also the choice to eventually leave the track (climbing a fence, crossing the street where forbidden. etc.) or to stand without moving, e.g. for a political protest.

Writing the city, on the other hand, requires acting physically on it, both on passages (building a bridge or road, placing objects in public spaces) and on and with surfaces (building walls, affixing, demolishing or coloring the objects of the city). Writing the city assumes often a character of rewriting, of superimposing new writing to an existing text. It means adding layers of meaning, removing and filling gaps, rectifying what already exists in an environment that is then continuously modified. It is, therefore, a form of bricolage that re-works already existing elements and materials. We can distinguish two polarities of citywriting: one involving the removal, at least partial, of the pre-existing substrate and the construction of something new, and one characterized by recovery, based on the transformation or resemantisation (reinterpretation) of existing urban objects.

The first form of city-writing requires both resources and power, and therefore is almost completely carried on by the authorities. This second, more common, form of rewriting, however, can exercised also by peripheral social actors: which occupy buildings, become squatters, camp in parks, write on the walls, open bars in abandoned factories or deconsacrated churches and so on. These rewritings, even when with practical purposes, cannot be regarded as exclusively functional: instead, they always have a highly communicative character. On the one hand, they affect the general meaning of the object that is resemantized, and, on the other hand, they become a way for individuals or for social political or religious groups, to engrave themselves within the city-text, to leave a trace, to represent their existence within the universe that the city represents.

Every action of urban gamification involves an act of enunciation or of writing of the city. This is one of its constituent traits and of its appeals: urban gamification can be a way for the citizens to reclaim their right to the city, as well as a way for gamifiers to attempt to influence the behavior of the citizens by rewriting the urban spaces around them.

\section{Digital cities: maps, virtual simulations and augmented reality}

The desire and need to map and represent the city run parallel with the tendency to give names to geographical locations. The urban text is surrounded by a dense network of meta-linguistic references that give a name to its various parts (roads, buildings, house numbers, districts, neighborhoods) later fixed in maps.

While that of urban mapping is a fascinating topic, for the purpose of this paper I will focus in particular on the digital declination of cartography (and not the analogue one). In the last decade, a great effort has been made to digitize and map the space - and in particular the urban space - especially by private actors [15]. The resulting digital maps pervade our everydaylife. These maps, however are more than mere reflections of the city: they are able to act and write on the city to a much greater extent that its analogical 
counterpart. As claimed by Ferraro [11], the cartographic representation of the city provided by a satellite navigation system, although quite simple, involves a shift in the balance of power between the city and its representation. These digital maps, in fact, can change before our eyes in accordance to our behavior: a mapping service making use GPS may redefine its paths following our position, it watches us, reconfigure itself and provides information of all kinds - not just about our position, but also about our speed and the possible paths to be taken depending on the selected values. Services such as Google Maps provide a complete and detailed mapping of the urban space, which not only incorporates the meta-linguistic signs of the city (street names etc.) but includes also numerous hypertextual links to the Web: homepages of hotels, restaurants and shops, user ratings of tourist attractions, pictures of the places of interest and so on. To this we must add social tagging mechanisms [24]. The digital map, then, acquires some of the characteristics of the real city: still a representation, it gets closer to the status of a prosthesis of the city.

Parallel to mapping, there is also a process of digital transposition or translation of urban spaces. In Google Street View urban areas are meticulously photographed, reconstructed and made available on the Web. This massive work of translation tries to recreate the city in all its semiotic richness, fixing its surfaces in digital images and reproducing virtually its paths. This virtual city is frozen in a collage of different moments and immutable paths, but nevertheless manages to roughly simulate the experience of moving through the city space. These new mapping strategies and translations of urban spaces are ontologically different from those of analogue maps: if once the map allowed to read the territory, remaining fundamentally submissive to the city (which imposed itself with its voluminous and irrefutable existence), digital maps are also able to write the territory, reinventing it according to their principles [11].

Moreover, urban areas are now saturated with telecommunication networks (Wi-Fi, GPS, GSM, ADSM and many others), channels that support the multiple facets of contemporary ICT. Among these there are some, in particular mobile and locative technologies, which are radically changing the relationship between citizens and city. Smartphones are capable, at the same time, to identify our position, to connect to the Web and to observe the surrounding environment through the lens of a camera and have become the key of access to multiple new ways of reading city spaces. Applications such as Foursquare, assign new values and meaning to businesses, others, such as Nike+ provide metrics about our movements to the city [1]. More importantly, augmented reality allows devices to offer their users information about their location, add new layers of meaning to the city spaces, even offers to the users themselves the possibility to leave comments and virtual graffiti while interacting with their surroundings through the screen.

Finally, several Augmenter Reality app combine digital maps and AR in order to offer their users a new way of experiencing the city [13]. This can be used also for creating games such as Ingress of Pokémon Go, effectively gamifying the act of moving through the city, with consequences that exceed the boundaries of a simple play activity [7] [5].

\section{A typology of urban gamification}

We have claimed that urban areas are communicative machines through which a culture represents itself and its way of seeing and describing the universe.

It is not surprising, then, if urban spaces are one of the areas touched by the ludicisation of culture. The city often becomes a playground, hosting playful activities and behaviors that escape from the places traditionally devoted to them. The very enunciation of these cities - the way we live them, cross them, interact with them - is becoming more and more playful, while extremely serious urban practices are reformulated or modified in order to follow this cultural change.

Ludicisation is also at the basis of many attempts of urban gamification and/or playification, which, in virtue of the new cultural centrality of play and games, actively seek to rewrite the urban spaces and make them, as much as possible, spaces in which is possible to play - and that, sometimes can be played. These activities take the form of pervasive play practices, as they involve a widening of the boundaries (spatial, temporal and social) of the play activity, which will then incorporate large portions of public space, moments not institutionally deputed to play and will involve unsuspecting passers-by [23].

The choices that lie behind the use of strategies of urban gamification may variate and range from the desire of (re)appropriating the territory to marketing techniques and comprehends the use of play for new forms of protest or to encourage new forms of citizenship. What all these forms of urban gamification have in common, however, is the desire to rewrite the city, to reshape it, to engrave oneself in it, to renew it 
by resorting to the energy and the ability to motivate people that emanates from play.

In order to facilitate the study of these activities, I will try to outline a possible typology of urban gamification, based on the semiotic properties of the city and of city-writing outlined above

First of all, we can separate different actions on the urban fabric on the basis of the authorial quality of the action. In other words, we can distinguish actions of urban writing from actions of urban enunciation. In the first case, the subjects have the power to change, in some measure, the urban fabric. Urban enunciation, on the other hand, has to do with the behavior and movement of the citizens. Crossing the city, moving through it, assembling in a specific place and dancing in public are all examples of city enunciation. It concerns anthropogenic practices that take place in the city and makes cultural events, shopping or protests assume carnivalesque and playful features. Both these kinds of action can be part of a gamified activity, and the same activity can sometimes involve actions of both kinds. Nevertheless, this distinction can be rather important for a typology of urban gamification, as it underlines the relationship that the participants will have with the city around them and their ability to engrave their own presence in it.

The authorial quality of the action is also one of the elements that determines another important category of actions of urban gamification: their durability. These actions can be inserted in a spectrum that goes from extremely ephemeral (the few minutes that it takes having a flash mob) to long lasting (when some form of permanent city-writing is involved).

The third element of our typology doesn't deal with the quality of the action but with is organization. We shall call it the direction of the urban gamification activity, which can be either bottom-up or top-down. The latter is generally accepted or promoted by power and involve citizens as participants in an activity designed to guide their behavior within the city. Bottom-up urban gamification, on the other hand, springs from the citizens themselves in a more or less chaotic way. It is generally rather confrontational with power and promotes city-writings and enunciations according to different logics, challenging the writings of the power by breaking the rules and resemantizing its texts.

The last two categories of my typology, finally, deal with the parts of the city involved. First, its dimension: whether the gamified activity acting on the city itself or on its digital maps. Second, what sort of elements are involved, passages or obstacles. This helps us distinguish activities that use the city as a stage, moving in its open spaces, occupying them, resemantizing them and the activities that act on the significant surfaces of the city.

\begin{tabular}{|l|l|}
\hline Category & Variables \\
\hline Authorial quality & writing and/or enunciating \\
\hline Durability & (spectrum) ephemeral to lasting \\
\hline Direction & bottom-up or top-down \\
\hline Dimension & analogue or digital \\
\hline Elements & passage and/or obstacle \\
\hline
\end{tabular}

Table 1. Typology of urban gamification

Given this typology, and the semiotic properties of the city outlined above, let's see and analyze a few examples.

\section{Examples of urban gamification}

\subsection{Flash-mobs}

Flash mobs, nowadays, are perhaps one of the most widespread practices of urban play. Often located in the city streets, in train stations or subways, flash mobs involve the sudden creation of a crowd of people making an unusual performance characterized by a playful character. These performances invade the space (both physical and social) of traditional events (protest marches, sit-ins, fairs) and often replace them as ways of aiming at the same objectives [31]. There are flash mobs of political protest, others that promote moments of sociability (e.g. the "dinners in white"), others that have commercial purposes or purely recreational (as are "zombie walks").

Flash mobs are ephemeral acts of enunciation that take place in the passages of a city: during flash mobs these spaces are transformed in improvised stages for shows that involve masking, playful carnivalesque traits, and surreal spectacles. Flash-mobs leave no trace behind it, if not in the memory of its participants and viewers. We face, then, a semiotic device aiming at gamification acting on the perceived border between everyday reality and play.

They are generally top-down, as they have organizers and participants that have prepared the action but aim to look spontaneous and to involve the other citizens in the playful action. Viewers of a flash mob, then, become players without their knowledge: the very communicative effectiveness of this practice is based on their interpretative disorientation, their temporary inability to distinguish between semiotic 
domains. Flash mobs play with the status of playfulness, they omit the message "this is play" [3] and entrust it to an implicit metacommunication: passers-by have to activate their competence in the semiotic domain of play in order to be able to correctly interpret the scene unfolding before their eyes.

The ludicisation of culture, then, is a prerequisite for an operation of flash-mob, as because the latter fits into a context where it is reasonable to expect that sometimes playfulness may invade everyday life. At the same time, however, flash mobs are also an act of gamification as it proposes as "playful", activities that are typically not, such as advertising or protests.

\subsection{Parkour}

Another interesting case of playful rewriting of urban spaces, this time concerning the ways the city is crossed, is that of parkour.

Parkour, born in the banlieues (suburbs) of Paris, particularly in Evry, began as a form of rebellion against the power's writing of the city. Evry is an artificial city inaugurated in the 1970s as the result of a top-down urban ideology that did imagine the city as a space completely regulated by the power, at whose center, functional and symbolic, stand the prefecture [18]. This project, therefore, failed at constructing that polyphonic and plural character that we have identified as a constituent of a city able to transform its inhabitants into citizens.

The urban writing in Evry, unsurprisingly, was perceived by its own inhabitants as an imposition, a vexation. The reaction of some of them took the form of a practice of rewriting the city with a strong playful component: parkour. This practice entails the tracing of an acrobatic alternative to the ways of crossing the city spaces prescribed by the power. It defines a new way of crossing the space [18] and, therefore, a new way of enunciating it and to make it meaningful.

Parkour is characterized, on the one hand, by speed (symbolic fruit of the conflicting relationship between the traceurs (practitioners of parkour) and power, which often results in them escaping from of the police) and on the other by an unusual way to relate to the obstacle. The obstacle, element used to create routes and regulate movement within the city, has a dual nature, symbolic and concrete, with which it guides those who travel in the city, dissuading them from leaving the track. The traceurs, however, reject the path imposed by the obstacle - which in the banlieues often prevents a fluid and rapid movement in space, forcing its inhabitants to long zigzagging - and replace it with an alternative route, which overcomes the obstacles with stunt jumping, transforming them into an opportunity to test physical and mental abilities. Obstacles, then, become material supports for a quick, fluid movement, implying a strong polemic towards the power that organized and traced that space in the first place.

If the speed of these enunciations makes parkour ephemeral, its most interesting characteristic, however is the relationship with the city's elements: during parkour several obstacles are treated as passages. The traceurs, then, modify the status of these elements, and their way of using them is juxtaposed to their design.

This reinforces the bottom-up nature of the activity, that is born spontaneously among the inhabitants of the banlieues and that becomes, for them, a way of reclaiming authorship within the city.

Parkour has clearly a playful component, as it can be interpreted as an attempt to resemantize in a playful way the urban space, it is manifested as a desire to turn the entire city into a huge playground, where all the elements of urban architecture - from the frames of the windows to the balcony railings, furniture bollards at bus shelters - are resemantized and re-functionalized in for urban entertainment, stripped of their practical functionality and covered with a playful functionality [18].

Parkour is then characterized by a threefold playful approach to the city: first of all, the traceurs carry out a play activity firmly engraved into the urban territory and therefore play in the city; Second, since during this practice they exploit the elements of the street furniture as supports, they also play with the city; Finally, as parkour is a form of opposition to the power and to its urban writings, the traceurs escape its logic and try to deceive them, hence playing the city itself.

It is interesting to note how this practice, which is together playful and politic, has also been influenced by ludicisation, ending up assuming, in certain cases, purely playful forms. The aesthetics of parkour are captured, among others, by a series of highly successful video games, Assassin's Creed, that features a sect of assassins (with a typical costume) using parkour to move through digital reconstructions of the largest cities of different historical periods. On the occasion of the eighth installment of the series - set in Paris during the French Revolution - a group of traceurs has made a video in which its members perform in the streets of Paris dressed just like the video game assassins. This video, which became immediately viral, shows a very different face of parkour, which, if it also retains some features of the conflict with power (in the video the assassins fight 
with monarchist soldiers), it still moves on the level of fiction and fun.

\subsection{Other}

There are of course many other examples that will have to be taken into consideration and that here we can only mention. The fact that the practice of city rewriting par excellence, graffiti, is often influenced by video games (see the work of French street-artist Invader) and, more recently, by internet memes, is rather interesting. In this case we might have bottomup lasing actions of writing on the obstacles of the city.

Some activities have a clearer aim at reappropriation, as Park(ing) day, a civil bottom-up festivity in which people from around the World rent parking spots but, instead of parking their car, they unroll some clods of grass, position some plants and create a small, green, park instead - again a bottom-up form of city-writing, that occupies the passages of the city for a short time.

There are also interesting top-down, coordinated projects such as Fun Theory from Volkswagen, that employ a more "classic" take on gamification trying to devise ways of influencing people's behavior through play, such as Piano Stairs, The World's deepest bin or the Speed camera lottery. Similarly, platforms such as Playable cities promote projects that make high use of technology in order to rewrite city experiences, for example recording the shadows of passers-by and projecting them a few minutes late (Shadowing) or allowing citizens to exchange texts with streetfurniture (Hello Lamp post). All these actions involve positioning technologically advanced objects within the city space (in its passages) and leave them there for a lasting period of time, in order to influence the citizens' behavior with fun or gameful interactions.

\section{Playing against maps}

The actions of urban gamification are not limited to the "analogue" dimension of the city. There are several actions that deal, instead, with the digitization of space and of cities in particular. It is important to keep in mind that the digitizing process is never neutral. In most cases, these operations are undertaken by private entities - Google, most of the times - and are driven by their business strategies and their systems of values. The digitization of the urban space is, in a way, an appropriation of public space by private companies, which realize a virtual copy of the city and retain its exclusive possession.
It is significant, then, to observe that the greatest resistance to this privatization of public spaces and to the imposition of rules to its mappings and reconstructions, has very often playful features. Despite the rulings of the European Court of Justice and Antitrust allegations, jokes and fun seem to be much more effective in mobilizing citizens against the strategies of these companies. I am talking, of course, about a playful resistance that never comes into direct conflict with the targeted companies, but that, however, attempts, perhaps unconsciously, to regain possession of privatized spaces using the playfulness as the main tool.

This playful resistance is formed by a bottom-up set of activities, which operates on both the enunciation and writing level. Enunciating a digital map equals to navigate through it (an ephemeral movement though its digital passages, enforced by the code) and to take screenshots or tag locations (a more lasting form of enunciation). Users often do not just "read" digital maps for practical matters, but they use them creatively. These digital representations of the city are often used to pursue playful aims, in open contradiction with their functional use proposed by their creators. Thousands of "hunters of curiosities" search every inch Google Street View looking for oddities and errors in digitization that will be immediately shared on-line and sometimes become viral memes. The digitized city becomes the ground of an immense treasure hunt.

Even the creation of these maps and of these virtual reproductions of cities is menaced by attempts to write on it in a playful way. Just like for real cities, individuals often try to engrave their presence in digital maps and translations - they try to leave a mark, to claim a role as co-authors. On Google maps, especially when the app was rather new, it used to be easy to find tags and descriptions that, before being detected and deleted by the moderators, can report misleading or ironic labels. The situation is even worse for Street View: despite the attempts to keep secret the path of the Google car, the latter increasingly finds photobomber in its way, people dressed as monsters, puppets arranged to look like living beings and so on a real carnival that is fixed into the digital images with which the virtual city will then be built. In these way citizens are able to write themselves both in the passage and the obstacles of the digital map, in way that are generally rather long-lasting. In some of the most notable cases, photobombers may "aim high", realizing some extensive works to be taken up by satellite and immortalized in the Google Earth maps, such as Where on Earth is Waldo? This installation, 
realized by Melanie Coles in Vancouver, compares the complexity and semiotic noise of the satellite-made map of Earth with the famous puzzle-books by Martin Handford.

If the map or the virtual reconstruction of the city are not faithful reproductions of urban spaces as they bear the inevitable authorial imprint left by the company that produces them, their final appearance will be also conditioned by a myriad of small disruptive actions that, although harmless, are capable of interfering and to engrave themselves in the heart of the maps made by Google.

Finally, the maps and digital reconstructions of the urban space also become subject of more extensive forms of writing. As it is harder to enforce control over digital maps than over real cities, it is rather common that citizens appropriate them. For example, the maps can be transformed into supports and basis to build video games. These games generally programmed by amateurs and therefore very simple: they focal point is the ability to attract and engage players allowing them to play in simulations of familiar places: in Street View Zombie Apocalypse, for example, the players can move in first-person in the streets portrayed by Google Street View, trying to escape poorly drawn zombies. Similarly, there are games that allow players to participate in some basic motor racing simulators on a virtual path overlapping the streets of Google maps. The representation of the city then, just like the city itself with urban games, is sometimes stripped of its functional values and becomes herself a playground, an object that can be resemantized and used in a playing activity.

These playful interpretations, reinterpretations and rewritings of maps and virtual representation of the urban area are, as we mentioned, different from the aims pursued, the company that owns them. We are facing, thus, one a conflict of power similar to those of the real cities. If these virtual and digital maps are contributing in a more and more crucial way to the readings and interpretations of the city by its inhabitants, the latter appear to resent the monolithic private power that controls them, and therefore they resolve to use subversive playfulness as a tool question it and reclaim, albeit in a, ephemeral way, the possibility of rewriting them and engrave themselves into them.

Nevertheless, if it is true that some of these actions are capable of bothering the private owners of the maps - as in the case of Google Shot View - a modification of Street View that allowed the player to walk around the virtual map armed of a combat rifle, immediately sued and shut down by Google - multinationals are also diverting the impulse of ludicisation in ways they can control, implementing games or Easter eggs. Google, for example, allowed the users of Maps to catch Pokémon in 2014 and to play Pac-Man on Google Maps in 2015.

More importantly, top-down actions of urban gamification are becoming more common. It is the case of Pokémon Go, which uses AR to insert game elements into the city transforming it in a playground, although without challenging it in any way. The most interesting aspect of AR urban gamification it's probably its ability to write upon the different elements city in a way that is both lasting (as it is consistent within the app) and ephemeral (as it is dependent on the use of the device, without leaving any other trace in the urban space).

\section{Conclusions}

In this paper we have seen how the city, a semiotic machine stupendously complex, as well as its innovative digital representations, is increasingly subject of playful resemantizations. Play is able to infiltrate several contexts and spaces, and to propose new meanings, new constraints, new strategies and new motivations.

The outlined typology might be rather useful to conceptualize and distinguish the types of action of urban gamification and to describe how they can influence the readings and interpretations of said spaces. It can be a useful tool both for describing and categorizing different already existing actions and to design new ones.

The typology itself, however, has to be considered in an early stage, and might very well be subject of expansion and improvement. In particular its descriptive capability should be tested on more case studies, in order to check the heuristic usefulness of the proposed categories. Finally, while this typology is based on the semiotic aspects of the city, there are other elements that influence urban gamification that can be equally important, such as design strategies, target participants and so on. For a more rounded typology, then, new expansions will be required from further work.

\section{Acknowledgments}

This project has received funding from the European Union's Horizon 2020 research and innovation programme under the Marie Sklodowska-Curie grant agreement No 793835.

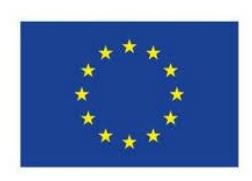

Marie Skłodowska-Curie Actions 


\section{References}

[1] Adlakha, D., Quantifying the Modern city: emerging Technologies and Big data for Active Living Research. Frontiers in public health, 5, 2017.

[2] Bakhtin, M., Rabelais and his World. Trans. Helene Iwolsky. Indiana University Press, Bloomington, 1988.

[3] Bateson, G., A theory of play and fantasy. Psychiatric research reports. 1955.

[4] M. Bonefant and S. Genvo, "Une approche située et critique du concept de gamification", Sciences du jeu 2, 2014.

[5] Boulos, M.., Lu, Z., Guerrero, P., Jennett, C., \& Steed, A., From urban planning and emergency training to Pokémon Go: applications of virtual reality GIS and augmented reality GIS in personal, public and environmental health, International Journal of Health Geographics, 16:7, 2017.

[6] Certeau, M. De, L'invention du quotidien, 1. Arts de faire, Union générale d'éditions, Paris, 1980.

[7] Colley, A., Thebault-Spieker, J., Lin, A. Y., Degraen, D., Fischman, B., Häkkilä, J., ... \& Wenig, D., The geography of Pokémon GO: beneficial and problematic effects on places and movement. In Proceedings of the 2017 CHI Conference on Human Factors in Computing Systems, ACM, 2017, pp. 1179-1192.

[8] A. De Souza e Silva, and L. Hjorth, "Playful urban spaces: A historical approach to mobile games". Simulation and Gaming, 40(5), 2009, pp. 602-625.

[9] S. Deterding, R. Kahled, L. E. Nacke and D. Dixon, "Gamification: Toward a Definition" in CHI 2011, May 712, 2011, Vancouver.

[10] Dunne, A., and F. Raby, Design Noir: The Secret Life of Electronic Objects. Birkhäuser, Basel, 2001.

[11] Ferraro, G., "Oltre l'idea di città", Lexia 1-2, Aracne, Rome, 2008, pp. 215-222.

[12] Fink, E., Oasi della gioia, Cutolo E. (trans.) Rumma, Salerno, 1969.

[13] Graham, M., Zook, M., \& Boulton, A., Augmented reality in urban places: contested content and the duplicity of code. Transactions of the Institute of British Geographers, 38(3), 2013, pp. 464-479.

[14] J. Hamari, J. Koivisto and H. Sarsa "Does gamification work? a literature review of empirical studies on gamification" in 2014 47th Hawaii International Conference on System Sciences, 2014, pp. 3025-3034.

[15] Hudson-Smith, A., "Digital urban - the visual city". UCL Working Papers Series 124, 2007.

[16] J. Huotari and K. Hamari "A definition for gamification: anchoring gamification in the service marketing literature", Electronic Markets 27(1), 2015, pp. 21-31.

[17] Kwak, N. H., Anti-gentrification Campaigns and the Fight for Local Control in California Cities. New Global Studies, 12(1), 2018, pp. 9-20.

[18] M. Leone, "Le Parkour sémiotique. Pratiche urbane di invenzione della naturalità", in Bonadei R. (ed.), NaturaleArtificiale. Il palinsesto urbano,: Lubrina Bergamo, 2009.
[19] J. M. Lotman, "L'architettura nel contesto della cultura", in S. Burini (ed.) Il girotondo delle muse. Saggi sulla semiotica delle arti e della rappresentazione, Moretti and Vitali Editori, Bergamo, 1998.

[20] Lynch, K., The Image of the City, MIT press Cambridge, 1960.

[21] Mastroianni, R, Writing the city. I Saggi di Lexia, Aracne, Rome, 2013.

[22] McGonigal, J., Reality Is Broken: Why Games Make Us Better and How They Can Change the World, Penguin Books, London, 2011

[23] Montola, M., Stenros, J. and A. Waern, Pervasive Games. Theory and Design, Morgan Kaufmann Game Design Books, San Francisco, 2009.

[24] Nam, H., \& Kannan, P. K., The informational value of social tagging networks. Journal of Marketing, 78(4), 2014, pp. 21-40.

[25] Nijholt, A. Playable Cities. Springer, Singapore, 2017.

[26] Örs, İ. R., Genie in the bottle: Gezi Park, Taksim Square, and the realignment of democracy and space in Turkey. In Toward New Democratic Imaginaries-İstanbul Seminars on Islam, Culture and Politics, Springer, Cham 2016, pp. 51-61.

[27] Salen, K., The Ecology of Games: Connecting Youth, Games, and Learning, MIT press, Cambridge, 2007.

[28] Sutton-Smith B. (1997) The ambiguity of play. Harvard University Press, Cambridge.

[29] Thibault M. (ed.), Gamification Urbana: Letture e Riscritture ludiche degli spazi cittadini, I Saggi di Lexia, Aracne, Rome, 2016.

[30] Thibault, M., "Play as a Modelling System - a Semiotic Analysis of the Overreaching Prestige of Games", Proceedings of the 1st International GamiFIN Conference, 2017, pp. 105-110.

[31] F. Turco, "Flash mob: quando la performance diventa strumento di protesta", Lexia 13-14, Aracne, Rome, 2012, pp. 305-319.

[32] Volli, U., Laboratorio di semiotica, Laterza, Bari-Roma, 2005.

[33] U. Volli, "Il testo della città — problemi metodologici e teorici", in M. Leone (ed.) Lexia 1-2, Aracne, Rome, 2008, pp. 9-12.

[34] Werbach K. and D. Hunter (2012) For the win, How Game Thinking Can Revolutionize Your Business, Wharton Digital Press, Philadelphia, 2012.

[25] Zuberi, D., \& Taylor, A., Securing the Urban Core: Policing Poverty and Migration in the Neoliberal City. Handbook on Migration and Security, 2017, pp. 144-160. 